\title{
Getting it off the ground
}

\section{Celebrating the centenary of controlled, powered flight.}

\section{The Wright Brothers and the Invention of the Aerial Age \\ by Tom Crouch \& Peter L. Jakab, National Geographic Books: 2003. 256 pp. US\$35, Can\$55}

\section{Wings of Madness: Alberto Santos-Dumont and the Invention of Flight}

by Paul Hoffman

Fourth Estate: 2003. 384 pp. $£ 10.99$

Hyperion: 2003. 369 pp. \$24.95

\section{Andrew Nahum}

A hundred years ago this week, Orville and Wilbur Wright made the first controlled, powered flight in a heavier-than air machine. By then it was becoming accepted that the idea of controlled flight might not be so fantastical after all. The scientific analysis of air and flying machines had begun to be taken seriously in the the nineteenth century by engineers and scientists such as Gustave Eiffel, Samuel Pierpont Langley and Hiram Maxim.

With the exception of Otto Lilienthal, who flew his hang-gliders repeatedly, few realized how capricious the air is. Although there was much debate about the correct expression for the resistance of the air, which would determine wing lift, the more immediate issues of pitch stability (controlling movement up and down), balance and control determined how long a 'flight' lasted before the almost inevitable crash. How many seconds this took seems rather unimportant now, but it still receives the attention of many partisan enthusiasts determined to prove that Richard Pearse in New Zealand, Langley in Washington, the German-American Gustavus Whitehead, or Clement Ader in France flew, or even 'could have flown', before the Wright brothers.

The reason for the Wright brothers' success was that they combined in their joint enterprise the best empirical skills of Yankee inventiveness, intelligent observation and a scientific, or at least systematic, investigation into flight. Furthermore, as cyclists and bicycle-makers, they understood the importance of piloting.

They sensed, in a way that almost no other flight pioneer except Lilienthal and the engineering scientist Percy Pilcher did, that a successful flying machine would not spring from the drawing board like a steam ship, ready to plough the aerial ocean. They knew that a flying machine might be successful but would still be nervy and treacherous, subject to the air currents of the moment. A bicycle might be an excellent machine, but the learner might still fall. They appreciated that learning to fly was different to the art of creating a successful machine, and set out to do both, or, in Wilbur's words, "to escape accident long enough to know how to avoid accident".

It is impossible to know exactly what each of the Wright brothers contributed to the venture, so close were they in everything. But of the two, Wilbur, who was destined for Yale before suffering some strange neurasthenic breakdown, seems to have been the more analytical. It was Wilbur who wrote of observing the flight of buzzards, and that "they regain their lateral balance, when partly overturned by a gust of wind, by a torsion of the tips of their wings". This observation translated into what was perhaps the Wrights' most notable achievement: the realization of the importance of control in the roll axis. Their contemporaries, in contrast, thought that adequate control and steering could be achieved purely by an elevator (pitch control) and a rudder (yaw control). The Wrights, however, understood that successful turns actually require the aircraft to bank, using a proportion of the lift force to initiate and sustain the turn.

Wilbur's systematic nature also led him to enquire about average wind speeds around the United States. He reasoned that because "it is necessary to move through the air at 15 or 20 miles an hour in order to obtain support, it is safer to practice in a wind, provided this is not too much broken up into eddies and sudden gusts by hills, trees and so forth". This insightful statement shows that he visualized the wind as a smooth, ideal flow, until it was perturbed by obstacles. This meteorological requirement took the brothers to Kitty Hawk, on an outer bank of the North Carolina coast where, during experimental sessions in 1900, 1901 and 1902, they developed their wing-warping gliders until they could fly smoothly and consistently.

To design the wing they also collected and collated data from Lilienthal and from their own wind-tunnel experiments on wing camber, coefficients of lift and drag, and the movement of centre of pressure with changing incidence. Their analysis indicates considerable mathematical ability for boys who left school at 17 , and is a remarkable tribute to the American public education system. At the same time they developed their piloting skills and their understanding of aircraft control so that, in the 1902 season, they were able to complete more than 700 successful glides, returning to Dayton to build an engine and attempt controlled, powered flight. None of their contemporaries made such persistent progress to airmanship or developed full, balanced, three-axis control (of pitch, yaw and roll) until the Wrights finally demonstrated this publicly in 1908 .

The excellent book by Tom Crouch and Peter Jakab is one of the first to speculate on the brothers' mentality, their home life and

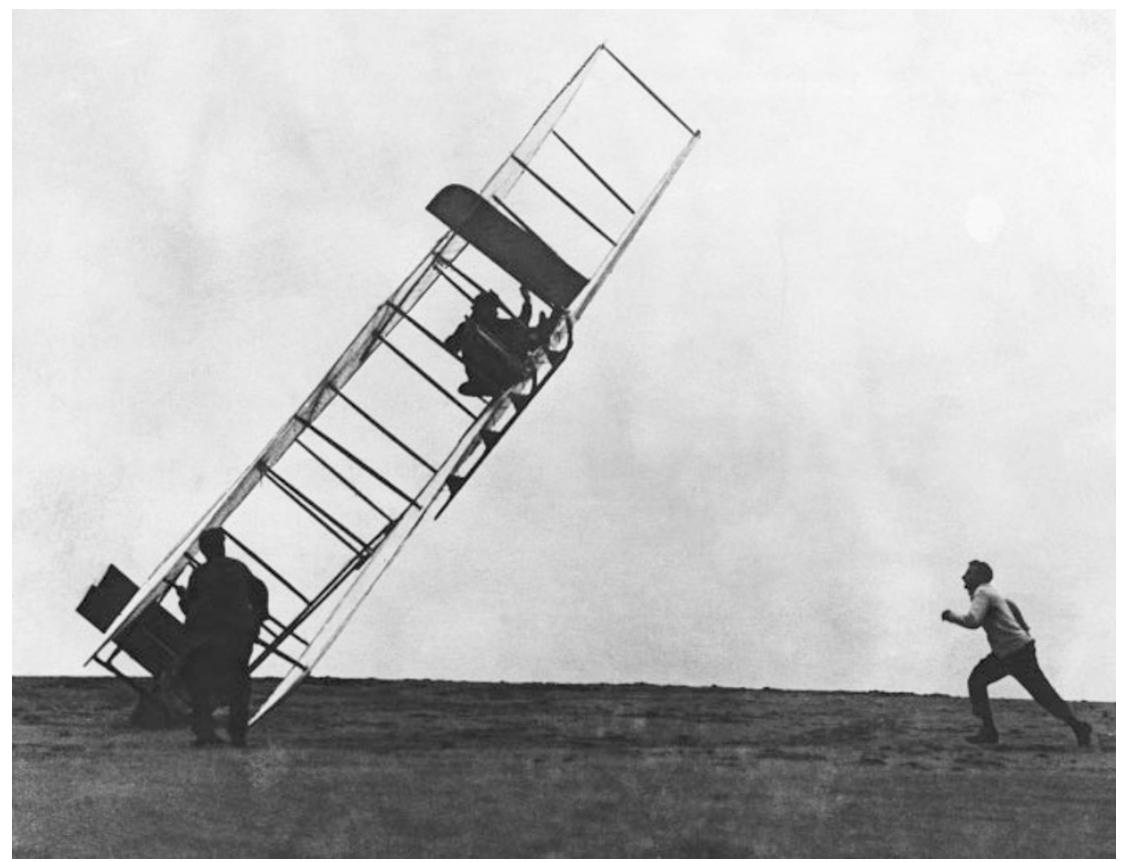

Trial and error: not all of the Wright brothers' test flights using gliders were entirely successful. 
the source of their originality. It contains a generous ration of the wonderful photographs taken by the Wright brothers of their gliding experiments, and forms an engaging account of these epochal events. However, those wanting more depth must go to the two authors' earlier books: Tom Crouch's The Bishop's Boys (W. W. Norton, 1989) and Peter Jakab's Visions of a Flying Machine (Smithsonian Institution Press, 1990).

The aviator and celebrity Alberto SantosDumont continues to puzzle and intrigue, but many details of his life have been obscure, his own book My Airships being one of the few sources of information. So Paul Hoffman's Wings of Madness is a much-needed and long-overdue account. It concentrates more on Santos Dumont's life than on the details of his flying machines. This fabulously rich Brazilian coffee tycoon settled in Paris and took his first free balloon flight with a professional balloonmaker in 1897, proving his scientific credentials by ascribing the extra effervescence of the champagne he took aloft to the high altitude. He soon progressed to small, light airships, initially using the remarkably light internal combustion engine developed for the De Dion-Bouton tricycle. SantosDumont became a popular figure as he dashed and sometimes crashed around Paris, often demonstrating remarkable control and mooring the craft outside his apartment on the Champs-Élysées.

By 1906, Santos-Dumont, stimulated by the move among French aeronauts to better what they had heard of the Wrights' flight, had built a heavier-than-air craft. The diminutive Santos-Dumont stood in the vehicle as it made a wallowing 240-metre flight in the Parc de Bagatelle. This public flight attracted media attention but the craft was barely under control and made no contribution to heavier-than-air flight.

When Wilbur Wright came to France in 1908 , Santos-Dumont seemed put out by the adulation that the American received, and began to show the beginnings of the depression and mental problems that would subsequently dog him. He became obsessed with new uses for aeroplanes. The final straw, which caused him to take his own life, was seeing the use of aeroplanes in the Brazilian revolution of 1932. His last recorded words are said to have been: "I never thought my invention would cause bloodshed between brothers. What have I done?"

Andrew Nahum is senior curator of the Aeronautical Collection at the Science Museum, Exhibition Road, London SW7 2UD, UK.

\section{A healthy draught of scepticism}

\section{Eight Preposterous Propositions: \\ From the Genetics of \\ Homosexuality to the Benefits of Global Warming \\ by Robert Ehrlich \\ Princeton University Press: 2003. 360 pp. \\ $\$ 27.95, £ 18.95$}

\section{Walter Gratzer}

A little way into Robert Ehrlich's assault on obfuscation and unreason, your appalled eye will light on a table which reveals that more than a quarter of the population of the United States believes in witches, $41 \%$ in possession by the devil, fully a half in extrasensory perception (ESP), and no less than $45 \%$ are in no doubt that extraterrestrial beings have been stalking the Earth. (The physicist Leo Szilard said so too, but added that they are called Hungarians.) Worse still, even among the beneficiaries of a college education, only $16.5 \%$ are prepared to concede that Homo sapiens is a product of evolution, unaided by the hand of God.

Such dense fog between the ears is invariably linked to an inability to grasp that improbable events are merely manifestations of the rules of chance, and not of divine intervention. Oscar Wilde understood this ingrained disorder of the human intellect: "Man can always believe the impossible, but man can never believe the improbable," he observed. Ehrlich has set himself the heroic task, concealed beneath

\section{Let it snow}

It is said that no two snowflakes are identical. Each contains about a billion billion water molecules, so the number of possible configurations is enormous. These photographs by Patricia Rasmussen are from The Snowflake: Winter's Secret Beauty by Kenneth Libbrecht (Voyageur Press, \$20).
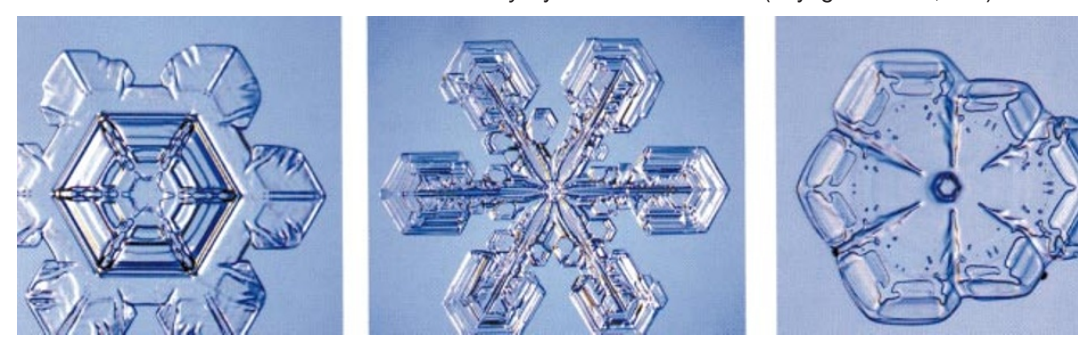

his flippant title, of confronting the tide of irrationality in what is in effect a manual of scientific reasoning.

His method, originating in his earlier book Nine Crazy Ideas in Science, is to test eight quite diverse propositions, extending from the unquestionably absurd (telekinesis, or moving matter around by thought alone) to the probably valid, such as a part for genetic factors in determining sexual inclination. He grades these on a scale of 'flakiness': zero flakes implies that the proposition may well be true, and four flakes that it is unarguably nonsense. My dictionary defines 'flaky' as "adj. eccentric, crazy", but this is not altogether what Ehrlich means by it; he conceives it as "lacking in empirical evidence or internal consistency", thereby distinguishing it from his 'crazy ideas' in science, some of which (like practically all of Kuhn's 'paradigm shifts') could be true.

Ehrlich's longest chapter is devoted to the weighty question: "Should you worry about global warming?” After an impeccably neutral analysis of the passionate opinions on either side, Ehrlich awards it a (judiciously qualified) 'one-flake' rating — in other words, a negative answer to the question could just about be entertained. A strength of Ehrlich's treatment is that he approaches the truly preposterous theses - telekinesis and the eclipse of evolution by "intelligent design" - with a straight face. His reasoned demolition of the evidence for these aberrations is vastly more effective than the red-eyed apoplexy that seizes the average scientist at their mere mention.

But it is the final two chapters that I found the most compelling. Ehrlich is at his most incisive on the placebo effect, and on the recent assertion in a widely publicized paper that its extent has been grossly exaggerated. The arguments hinge, for the most part, on the interpretation of statistics, which Ehrlich manages to make accessible to all who will make the effort. Only at one point, isolated in a box from which innumerate readers can avert their eyes, does he set out the mathematics in full.

He makes a powerful case that many, and especially psychotropic, drugs which make extravagant profits for the pharmaceutical industry are ineffective or worse. He uncovers the weaknesses in conventionally designed double-blind trials and, both here and in his final chapter ("Should you worry about your cholesterol?"), he expatiates on the lax standards by which the industry is now regulated, and the way in which the once-proud US Food and Drug Administration has been emasculated. What is especially striking is the low confidence limit $(P<0.05)$ considered adequate to establish the efficacy of a new drug in clinical trials - a level that is perhaps acceptable in sociological research, but is generally considered risible in the exact sciences. 